\title{
Cat scratch colon. A new ethiopathogenic possibility
}

\author{
G. Payeras, R. Briz, R. Barranco, A. Calvache and P. Castro \\ Hospital Infanta Elena. Madrid, Spain
}

\section{CASE REPORT}

Our case describes an 80-year-old female who presented an asymptomatic lower intestinal bleeding after depositions without hemodynamic repercussion, rectal tenesmus or abdominal pain. She relates alternating constipation and diarrhea in the last twenty years without recent changes. Colonoscopy (done under sedation): Hemorrhoids grade III/IV. Pancolonic diverticulosis. In the cecum mucosa, numerous lineal erosions, 3 to $4 \mathrm{~cm}$ long, with inflammatory appearance were found. Ileocecal valve and the fifteen last centimeters of ileum displayed no pathological findings or traces of blood. Biopsies of colonic mucosa did not show any sign of inflammation.

\section{DISCUSSION}

There has been recently described a new endoscopy entity defined as "cat scratch colon". It is defined as the presence of linear mucosal breaks in the cecum and ascending colon, of variable length, brightly red colored, resembling a cat scratch (1) (Fig. 1). To date, very few cases have been reported. These lesions are usually superficial, involving only the mucosal layer (Fig. 2), and cause no clinical manifestations. Nevertheless, the lesions can sometimes be deeper and cases of pneumoperitoneum have been described (2).

The cause of these lesions is unclear. It has been suggested that they may be due to traumatic injury associated with compression, distension, stretching during endoscopy procedure, or to an excessive air insufflation during endoscopy (3), particularly if the elasticity of the colonic mucosa is decreased, as it is the case of the collagenous colitis (4). In our partic-



Fig. 1

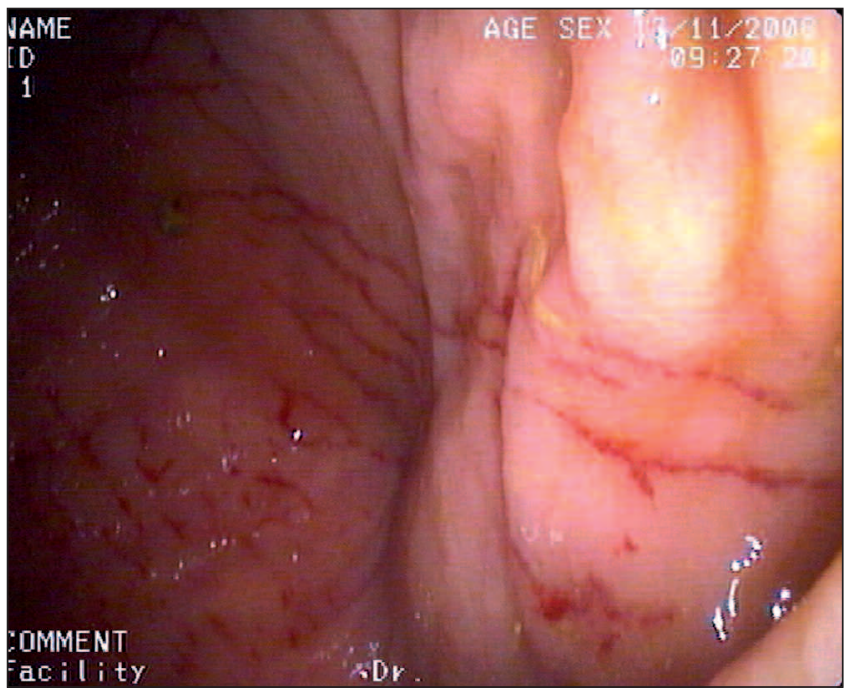

Fig. 2 
ular case, because of the presence of a large number of diverticula, air insufflation was negligible; the cecum was reached easily without having to perform traumatic maneuvers to the colonic mucosa. Moreover, biopsy did not show findings compatible with collagenous colitis. Because the patient was taken nonsteroidal anti-inflammatory drugs, we suggest that these drugs might be the cause of this endoscopic finding.

\section{REFERENCES}

1. Baudet JS, Arguiñarena X, Díaz-Bethencourt D, Soler M, Avilés J. Colon en arañazo de gato. Una entidad poco conocida. Rev Esp Enferm Dig 2008 ; 100 (12): 790-1.

2. Komuro Y, Watanabe T, Hata K, Nagawa H. Diversion colitis with a mucosal tear ron endoscopic insulflatin. Gut 2003; 52: 1388-9.

3. Woltjen JA. A retrospective analysis of cecal barotrauma caused by colonoscope air flow and pressure. Gastrointest Endosc 2005; $61: 37-45$.

4. Mc Donell WM, Loura F, Pointon MJ, Greenson JK. Cat scratch colon. Endoscopy 2007; 39: 459-61. 